\title{
The impacts of BSMV on vegetative growth and water status in hulless barley (Hordeum vulgare var. nudum) in VIGS study
}

\author{
Junjun Liang' ', Xin Chen ${ }^{1,2}$, Huanhuan Zhao', Shuiyang Yu' ', Hai Long', Guangbing Deng' ', Zhifen Pan', \\ Maoqun $\mathrm{Yu}^{1 *}$ \\ 'Chengdu Institute of Biology, Chinese Academy of Sciences, No. 9 Section 4, Renmin South Road, Chengdu 610041, China \\ ${ }^{2}$ College of Life Sciences, Sichuan University, No. 24 South Section 1, Yihuan Road, Chengdu 610065, China
}

\begin{abstract}
Barley stripe mosaic virus (BSMV) is an established and extensively used virus-induced gene silencing (VIGS) vector for gene function analysis in monocots. However, the phenotypes generated by targeted gene silencing may be affected or masked by symptoms of BSMV infection. To better understand the potential effects of BSMV-VIGS in hulless barley (Hordeum vulgare var. nudum), the accumulation pattern of BSMV and its impacts on vegetative growth and water status were investigated. The results indicated that the vegetative growth of infected plants was significantly and continuously impacted by BSMV from 10 to 40 days post inoculation (dpi). When the accumulation of BSMV was extremely high (7 to $11 \mathrm{dpi}$ ), infected plants displayed twisted leaf tips with an increased water lose rate (WLR) and decreased water content (WC). Virus accumulation declined and stabilized after $25 \mathrm{dpi}$, at this stage, the WLR and WC were unaffected in the infected plants. The efficiency of VIGS was tested by the silencing of Phytoene desaturase (PDS). RT-qPCR indicated that BSMV-VIGS can be sustained with good efficiency for up to 40 dpi under an altered condition with lower temperature $\left(22 \pm 1^{\circ} \mathrm{C}\right)$ and higher relative humidity $(70 \pm 10 \%)$. It was concluded that 25 to $40 \mathrm{dpi}$ was the appropriate time zone for drought-related gene analysis by BSMV-VIGS under such condition.
\end{abstract}

Keywords: hulless barley (Hordeum vulgare var. nudum); VIGS; BSMV; virus reproduction; vegetative growth; water retention capacity

\section{Introduction}

Virus-induced gene silencing (VIGS) has been developed as an important tool for gene function analysis [1-3]. This method has several advantages over conventional transgenic technologies in that it is easy to manipulate, saves time and has a low cost [4]. Barley stripe mosaic virus (BSMV) is a Hordeivirus which can cause mild to moderate mosaic symptoms $[4,5]$. It has been genetically reconstructed to a VIGS vector for monocots [6] and has been widely utilized in gene silencing [6-13].

However, there are some drawbacks in utilizing BSMVVIGS, in that the high virus level can alter plant development, particularly in relation to height and leaf morphology [4]. The infection of BSMV can cause non-specific stress responses, resulting in delayed biosynthesis processes and accelerated senescence [14]. Such results could mask, or be confused as, effects of gene silencing. Progeny testing of infected plants can be used to obtain a mild viral symptom in

\footnotetext{
* Corresponding author. Email: yumaoqun@cib.ac.cn
}

Handling Editor: Przemysław Wojtaszek order to elucidate the true effects of VIGS $[15,16]$, however the extra time taken mitigates one of the primary advantages of the quick results that this method offers.

Tibetan hulless barley (Hordeum vulgare var. nudum) is an annual, self-pollinated species with adaptations to drought, salinity and low temperature conditions associated with its domestication on the Qinghai-Tibet plateau. These hulless barleys grow on a broad range of environments with large differences in water availability, temperature and soil type, giving rise to a range of adaptive diversity to abiotic stresses. Thus they are likely to contain good sources of drought resistance alleles suitable for breeding purposes [17]. Identifying genes involved in the drought tolerance is a challenge as this a quantitative trait that involves many metabolic pathways. VIGS is a potential tool to help characterize the functions of prospective stress-response genes [18]. However, to apply BSMV-VIGS in characterizing drought stress related candidate genes, it is important to understand how BSMV accumulation affects plant morphology, vegetative growth and water retention capacity of Tibetan hulless barley.

Phytoene desaturase (PDS) is normally used as a reporter gene to test if a VIGS vector works in a certain species and can be used as an indicator to show the best time period 
for gene silencing. The reduction or loss of this enzyme results in inhibition of the carotenoid biosynthesis pathway leading to a photo-bleaching phenotype due to chlorophyll photo-oxidation [1,19-22].

In this study, the relationship between BSMV virus accumulation and its impact on vegetative growth and water retention capacity of Tibetan hulless barley was analyzed from 10 to 40 days post inoculation (dpi). BSMV accumulation was checked by quantitative reverse transcription polymerase chain reaction (RT-qPCR) and its effect on plant height, total dry weight (TDW), water loss rate (WLR) and water content (WC) was investigated. Plant growth conditions were optimized with lower temperature $\left(22 \pm 1^{\circ} \mathrm{C}\right)$ and higher relative humidity $(70 \pm 10 \%)$. The efficiency of gene silencing under thus condition was analyzed from 7 to 60 dpi using PDS as an indicator. The impacts of PDS silencing on vegetative growth and water retention capacity and the possibility of setting $P D S$-silenced plants as a control group to compare phenotype changes caused by targeted gene silencing were also investigated.

\section{Material and methods}

\section{Plant material and growth conditions}

The hulless barley line Z033 is drought tolerant and has good early vigor [23] and was employed for BSMV inoculation. All seeds were germinated in half-strength Murashige and Skoog (MS) solid medium for $3 \mathrm{~d}$ and uniformly germinated seeds were transplanted into plastic pots ( $5 \mathrm{~cm}$ in height and $5 \mathrm{~cm}$ in diameter; one plant per pot) that contained $100 \mathrm{~g}$ of potting mixture. The potting mix consisted of local soil, nutrient soil and vermiculite (7:2:1, $\mathrm{v}: \mathrm{v}: \mathrm{v})$. The seedlings were cultivated in a greenhouse with a temperature range of $22 \pm 1^{\circ} \mathrm{C}$, a relative humidity of $70 \pm 10 \%$ and a photoperiod of $16 \mathrm{~h} / 8 \mathrm{~h}$ (light/dark). All plants were watered every second day and pots were free draining.

\section{BSMV inoculation}

The BSMV vectors BSMV-a (U35767.1), BSMV- $\beta$ (U35770.1), BSMV:GFP and BSMV:PDS were kindly provided by Prof. Daowen Wang (Institute of Genetics and Developmental Biology, Chinese Academy of Sciences, Beijing, China). Genomic organization of BSMV (ND18 strain) RNAs $\alpha, \beta$ and $\gamma$ were described by Zhou et al. [24]. RNA $\beta$ do not have the coat protein beta A deletion. The vector, BSMV:GFP was previously described in Haupt et al. [25] and its sequence is listed in Tab S1. A PDS of $200 \mathrm{bp}$ was inserted in an antisense orientation (Fig. S1) to form the construct BSMV:PDS. The sequence of BSMV:PDS is listed in Tab. S2. The plasmid components of BSMV- $\alpha$ and BSMV- $\gamma$ (BSMV:GFP and BSMV:PDS) were linearized by MluI while the BSMV- $\beta$ plasmid was linearized by SpeI, extracted with phenol/chloroform and used as templates for in vitro transcription by the RiboMAX ${ }^{\mathrm{s}}$ Large Scale RNA Production System-T7 (Promega, United States) with Ribo $\mathrm{m}^{7} \mathrm{G}$ Cap Analog (Promega) for $3 \mathrm{~h}$ at $37^{\circ} \mathrm{C}$. The three viral RNA components were first mixed using a 1:1:1 (v:v:v) ratio, then the combined components were mixed with nuclease-free water and GKP buffer [50 mM glycine, $30 \mathrm{mM}$ dipotassium hydrogen phosphate, $\mathrm{pH} 9.2,1 \%(\mathrm{w}: \mathrm{v})$ bentonite, and $1 \%$ $(\mathrm{w}: \mathrm{v})$ celite] with a ratio of $1: 3: 4(\mathrm{v}: \mathrm{v}: \mathrm{v})$. Three leaf stage seedlings ( $3 \mathrm{rd}$ leaf less than $5 \mathrm{~cm}$ ) were inoculated with $8 \mu \mathrm{l}$ of this mixture, with the solution being applied with gentle strokes using rubber gloves to the bottom of the second and the third leaves. For mock inoculation on control seedlings, $8 \mu$ of nuclease-free water and GKP buffer in a 1:1 (v:v) ratio was applied as described above. After inoculation, the seedlings were fog sprayed with nuclease-free water and covered with plastic film to maintain high humidity for $3 \mathrm{~d}$. All the inoculated and control plants were maintained in a greenhouse with a temperature range of $22 \pm 1^{\circ} \mathrm{C}$, a relative humidity of $70 \pm 10 \%$, and a photoperiod of $16 \mathrm{~h} / 8 \mathrm{~h}$ (light/ dark). All plants were watered every alternate day to soil water holding capacity.

\section{Biomass accumulation tests}

Plants were harvested at 10,20, 30 and 40 days post inoculation (dpi). Entire plants were harvested (soils adhering to the roots was gently removed), and placed in a $70^{\circ} \mathrm{C}$ oven for $3 \mathrm{~d}$ to dry. Roots and the aerial parts of the plant were weighed separately. Biomass accumulation was determined by TDW.

\section{Water loss rate and water content analysis}

WC was used for the investigation of water status of BSMV-infected and mock-inoculated control plants under optimized condition with normal water supply. A $10 \mathrm{~cm}$ leaf length was collected from the newest leaves by excising the newest leaf to its base (if this was less than $10 \mathrm{~cm}$ ) and making up the remaining length with the penultimate leaf, as measured from the leaf base. These were weighed to calculate fresh weight (FW) and oven dried at $70^{\circ} \mathrm{C}$ for $3 \mathrm{~d}$ to calculate dry weight (DW). WC, as a percentage of fresh mass, was calculated according to the following formula: $\mathrm{WC}=(\mathrm{FW}-\mathrm{DW}) / \mathrm{FW}$.

To investigate the water holding capacity of BSMVinfected and mock-inoculated controls under detached drought stress, WLR of excised newly grown leaves were measured as described by a detached drought stress as previously reported [23] at 10, 20, 30 and $40 \mathrm{dpi}$. WLR over $6 \mathrm{~h}$ was calculated by the following formula: $\mathrm{WLR}_{6}\left(\mathrm{~g} \mathrm{~h}^{-1}\right.$ $\left.\mathrm{g}^{-1} \mathrm{DW}\right)=\left(\mathrm{FW}-\mathrm{W}_{6}\right) /(\mathrm{DW} \times 6)$, where $\mathrm{FW}$ : fresh weight, $\mathrm{W}_{6}$ : weight of $6 \mathrm{~h}, \mathrm{DW}$ : dry weight).

\section{RT-qPCR analysis}

Total RNA from the newly grown leaves $(10 \mathrm{~cm}$ leaf length, as described above) of BSMV:PDS-inoculated plants and BSMV:GFP-inoculated plants were isolated every two days from 7 to $19 \mathrm{dpi}$ and every five days from 25 to $60 \mathrm{dpi}$ (each sample contained leaves from at least 5 individual plants). A total of $5 \mu \mathrm{g}$ RNA were treated with DNaseI and used for first-strand cDNA synthesis using M-MLV reverse transcriptase (TaKaRa). The cDNA reaction mixture was diluted tenfold, and $1 \mu \mathrm{l}$ was used as a template in a $20-\mu \mathrm{l}$ PCR reaction. PCR was performed after pre-incubation at $95^{\circ} \mathrm{C}$ for $5 \mathrm{~min}$ followed by 40 cycles of denaturation at $95^{\circ} \mathrm{C}$ for $15 \mathrm{~s}$, annealing at $60^{\circ} \mathrm{C}$ for $15 \mathrm{~s}$, and extension at $72^{\circ} \mathrm{C}$ for $15 \mathrm{~s}$. All the reactions were performed in the Chromo4 real-time PCR detector system (Bio-Rad) using 
iQ SYBR green supermix (Bio-Rad). To normalize the cDNA templates, the housekeeping gene elongation factor $1 \alpha(E F)$ was co-amplified. All primers were synthesized by Invitrogen (Shanghai, China). Their sequences and efficiency are shown in Tab. 1. The primers, PDS P1 and P2, which are designed for $P D S$ expression analysis, targeted regions of $P D S$ other than the section used for silencing. The amplification specificity was checked with a heat-dissociation protocol (melting curves in the 65 to $95^{\circ} \mathrm{C}$ range) as a final step of the PCR. Primer pairs showed a single peak on the melting curve, and a single band with the expected size was detected by agarose gel electrophoresis.

Tab. 1 PCR primers used to amplify reference and target genes.

\begin{tabular}{|c|c|c|c|}
\hline Name & Primer sequences & Product size & Efficiency \\
\hline $\mathrm{EF}$ & $\begin{array}{l}P_{1:}: 5^{\prime} \text {-AAGGATCTCAAGCGTGGG-3' } \\
\text { P2: 5'-GTGGGATGTGTGGCAGTC-3' }^{\prime}\end{array}$ & 154 bp & $102.30 \%$ \\
\hline PDS & $\begin{array}{l}\text { P1: 5'-CACTTACTGACGGGACTCA-3' } \\
\text { P2: 5'-AGAAGGTGGTCGTATGTGTT-3' }\end{array}$ & 198 bp & $99.96 \%$ \\
\hline BSMV- $\alpha$ & $\begin{array}{l}\mathrm{P}_{1}: 5^{\prime} \text {-AGAAGGTAACAGGGACGGTG-3' } \\
\mathrm{P}_{2}: 5^{\prime} \text {-TGAGTGTGATGGAGTTGACC- } 3^{\prime}\end{array}$ & 178 bp & $89.10 \%$ \\
\hline BSMV- $\beta$ & $\begin{array}{l}\text { P1: 5'-ACTTTAGCGTTGCTTCCTCTC-3' } \\
\text { P2: 5'-CGATTGTTGTGCGGCTGA-3' }\end{array}$ & 219 bp & $103.00 \%$ \\
\hline BSMV- $\gamma$ & $\begin{array}{l}\text { P1: 5'-GTCCTTACGCTTTCATCACCT-3' } \\
\text { P2: 5'-TTCAGACGGAGAACAGGCG-3' }\end{array}$ & $245 \mathrm{bp}$ & $94.73 \%$ \\
\hline PDSs & $\begin{array}{l}P_{1:}: 5^{\prime} \text {-TGGCTAAGCTTGAAAGTGAGG - } 3^{\prime} \\
\mathrm{P}_{2}: 5^{\prime} \text {-GTGGACTTGCAAACACTCC-3' }\end{array}$ & 396 bp & \\
\hline
\end{tabular}

EF: elongation factor $1 \alpha$; PDS: Phytoene desaturase; BSMV- $\alpha,-\beta$ and $-\gamma$ represent the three components of barley stripe mosaic virus; PDSs: situated at both sides of the PDS insert on BSMV- $\gamma$

\section{The stability of BSMV-VIGS}

The insertion site flanking primers for BSMV- $\gamma$, named PDSs P1 and P2, were designed for the amplification of the silencing inducing fragment (the PDS insert) and subsequent sequencing (Fig. S1). Their sequences are shown in Tab. 1. The PCR products from the cDNA templates of control plants and BSMV:PDS-inoculated plants (7 to $60 \mathrm{dpi}$ ) were checked by agarose gel electrophoresis. Products with expected sizes from BSMV:PDS-inoculated plants at 45, 50, 55 and $60 \mathrm{dpi}$ were sequenced at GENEWIZ (Suizhou, China).

\section{Data analysis}

Means, standard deviation $(S D)$, standard error $(S E)$ of plant height, TDW, WLR, WC and expression data (RTqPCR results) were performed using the SPSS package (version 17.0, SPSS Inc.). All data obtained were subjected to one way analysis of variance (ANOVA) and the mean differences were compared by the least significant difference (LSD) test. All analyses were conducted according to a completely randomized design.

\section{Results}

\section{Dynamic accumulation of BSMV from 7 to $60 \mathrm{dpi}$}

The accumulation of BSMV- $\alpha$, BSMV- $\beta$ and BSMV- $\gamma$ from 7 to 60 dpi was analyzed by RT-qPCR and the results showed similar accumulation patterns (Fig. 1). BSMV accumulation in BSMV:PDS-inoculated plants reached a peak from 7 to $11 \mathrm{dpi}$ and declined from 11 to $17 \mathrm{dpi}$. After 25 dpi, BSMV:PDS was at a low and relatively stable level.
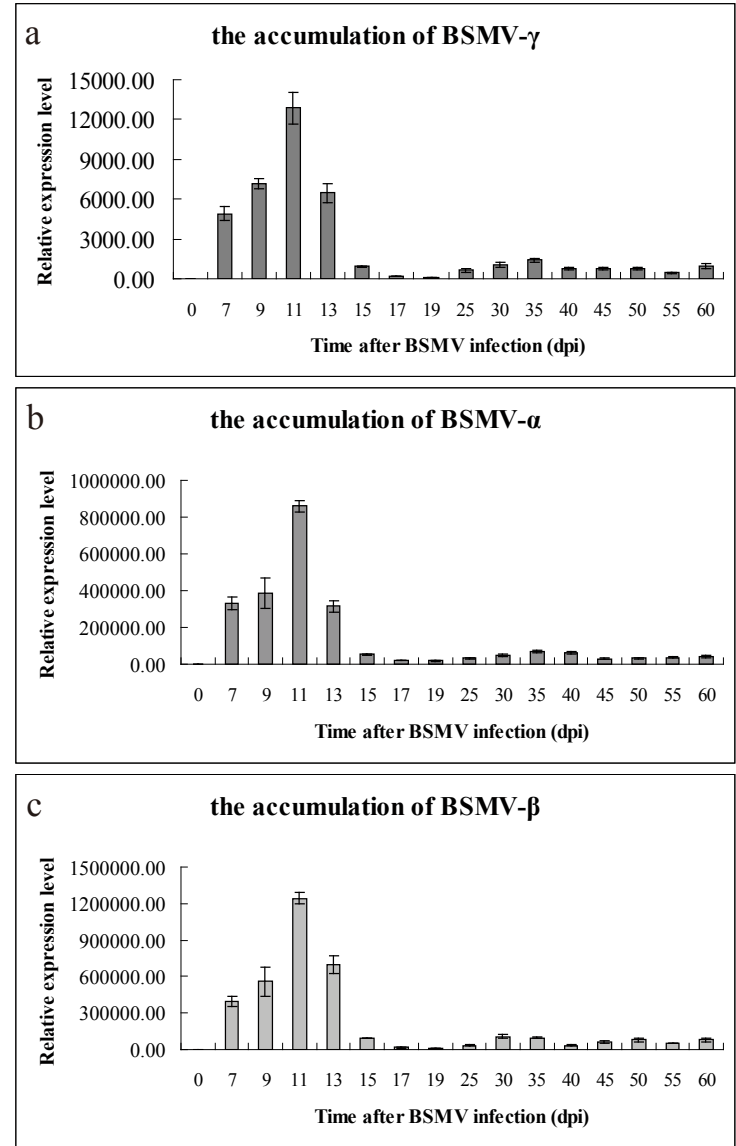

Fig. 1 The accumulation of BSMV- $\gamma(\mathbf{a}), B S M V-\alpha(\mathbf{b})$ and BSMV- $\beta$ (c) from 7 to 60 dpi. Barley stripe mosaic virus (BSMV) accumulation in BSMV:PDS-inoculated plants was analyzed by quantitative reverse transcriptase polymerase chain reaction (RT-qPCR) using elongation factor $1 \alpha(E F)$ as the reference from 7 to 60 days post inoculation (dpi). 0 dpi refers to mock-inoculated wild type (WT) control plants (three- to four-leaf stage). Each sample contained newly grown leaves from at least 5 individual plants. All data represent the average value of three technical repeats and are shown as the means $\pm S D(n=3)$.

\section{The impacts of BSMV accumulation on plant growth}

Plant height and the TDW of BSMV-infected plants and mock-inoculated wild type (WT) controls were measured at 10, 20, 30 and 40 dpi (Fig. 2, Fig. 3a,b). Average height of BSMV-infected plants were significantly $(P<0.05)$ shorter than controls at all time points (Fig. 2, Fig. 3a). TDW of BSMV:GFP-inoculated and BSMV:PDS-inoculated plants also showed lower values than controls from 10 to $40 \mathrm{dpi}$ (Fig. 3b). At 10 dpi, the mean TDW of BSMV:GFP-inoculated infected plants were $25 \mathrm{mg}$ less than the control, and the difference increased to $53 \mathrm{mg}$ and $98 \mathrm{mg}$ at 20 and $30 \mathrm{dpi}$, and finally to $282 \mathrm{mg}$ at $40 \mathrm{dpi}$. The morphology of the leaves were also monitored at 10, 20, 30 and $40 \mathrm{dpi}$ (Fig. 4), with the blades in BSMV-infected plants being significantly smaller at 30 and 40 dpi when compared to controls. Furthermore, 


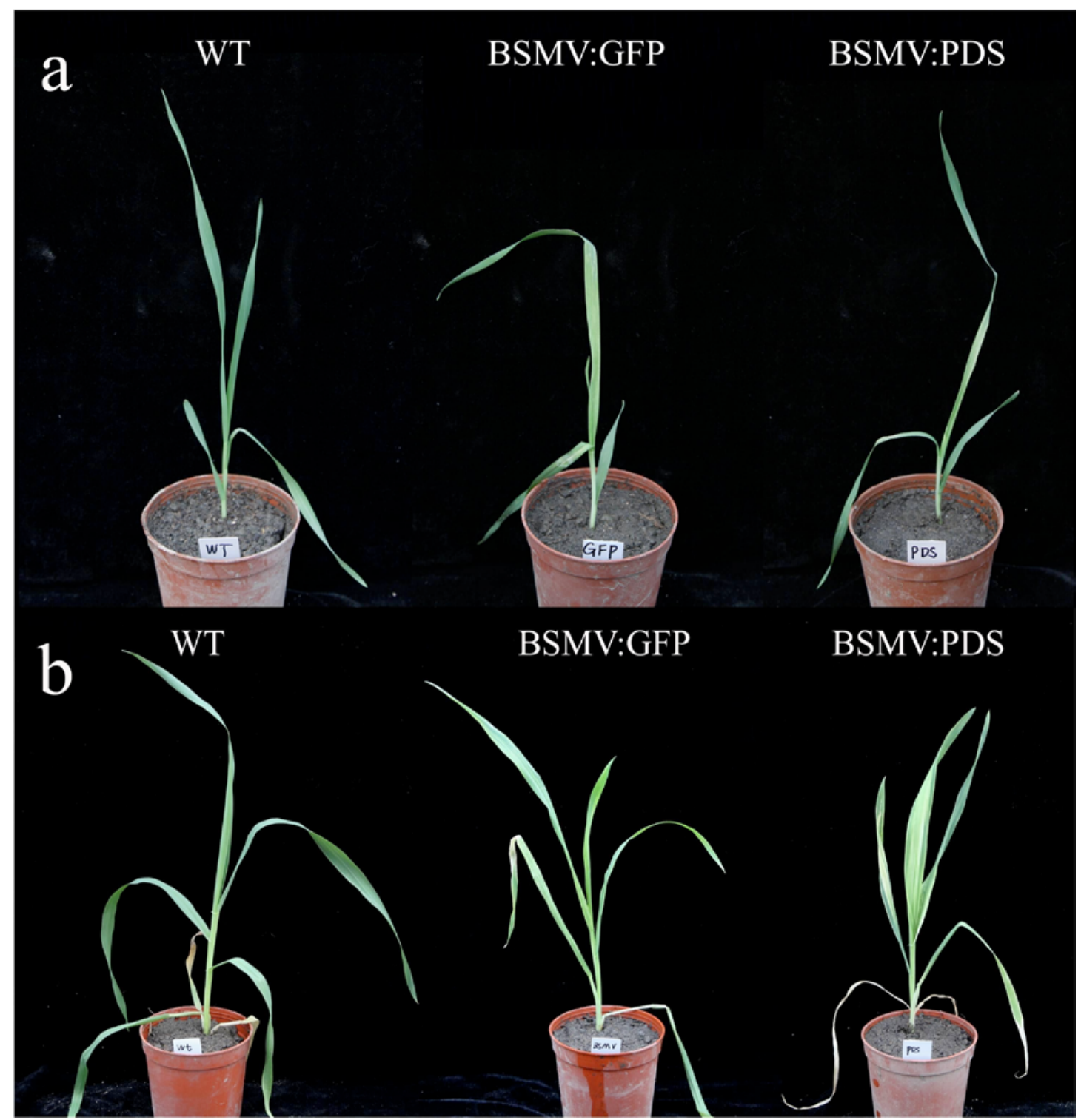

Fig. 2 Comparison of the vegetative growth state of mock-inoculated wild type (WT) control plants and BSMV-infected plants. (a) and (b) indicate the vegetative growth of mock-inoculated WT control plants, BSMV:GFP-infected and BSMV:PDS-infected plants at 10 and 30 days post inoculation (dpi) respectively. WT - mock-inoculated WT control plants; BSMV:GFP - plants inoculated by BSMV:GFP vector; BSMV:PDS - plants inoculated by BSMV:PDS vector.

lower values of TDW of the root system in all BSMV-infected plants indicated decreased biomass accumulation in roots after infection. (Fig. 3c).

The impacts of $P D S$ silencing on vegetative growth was also measured. The height of BSMV:GFP-inoculated plants was significantly higher than BSMV:PDS-inoculated plants at $10 \mathrm{dpi}$, but showed no obvious differences from 20 to 40 dpi (Fig. 3a). The biomass accumulation of BSMV:GFPinoculated plants was significantly higher than BSMV:PDSinoculated plants at 20 and $30 \mathrm{dpi}$, but showed no significant $(P<0.05)$ differences at $40 \mathrm{dpi}$ (Fig. 3b).

\section{The impact of BSMV on the water retention capacity}

The 6-h WLR of BSMV-infected plants were significantly $(P<0.05)$ higher than that of mock-inoculated WT controls at 10 and $20 \mathrm{dpi}$ (Fig. 5a). The water status under normal growth conditions was also investigated using WC as an indicator. The WC of all the BSMV-infected plants was significantly $(P<0.05)$ lower than that of controls at $10 \mathrm{dpi}$ (Fig. 5b). Distinct from controls, the leaf tips of these plants became withered and twisted (Fig. 4).

The 6-h WLR of BSMV-infected plants showed no significant differences $(P<0.05)$ with the controls at 30 and 40 dpi (Fig. 5a). The WC of the BSMV:GFP-inoculated plants also showed no significant differences $(P<0.05)$ at 20 and $30 \mathrm{dpi}$, but was higher than the controls at $40 \mathrm{dpi}$ (Fig. 5b). These results indicated that the impact of BSMV on WLR and $\mathrm{WC}$ reduced after $20 \mathrm{dpi}$.

The influence of PDS silencing on WLR and WC was also investigated. The 6-h WLR of BSMV:PDS-inoculated plants was higher than that of BSMV:GFP-inoculated plants at $10 \mathrm{dpi}$ and significantly $(P<0.05)$ higher than BSMV:GFPinoculated plants at $20 \mathrm{dpi}$ (Fig. 5a). The WC of BSMV:PDSinoculated plants was significantly $(P<0.05)$ lower than that 


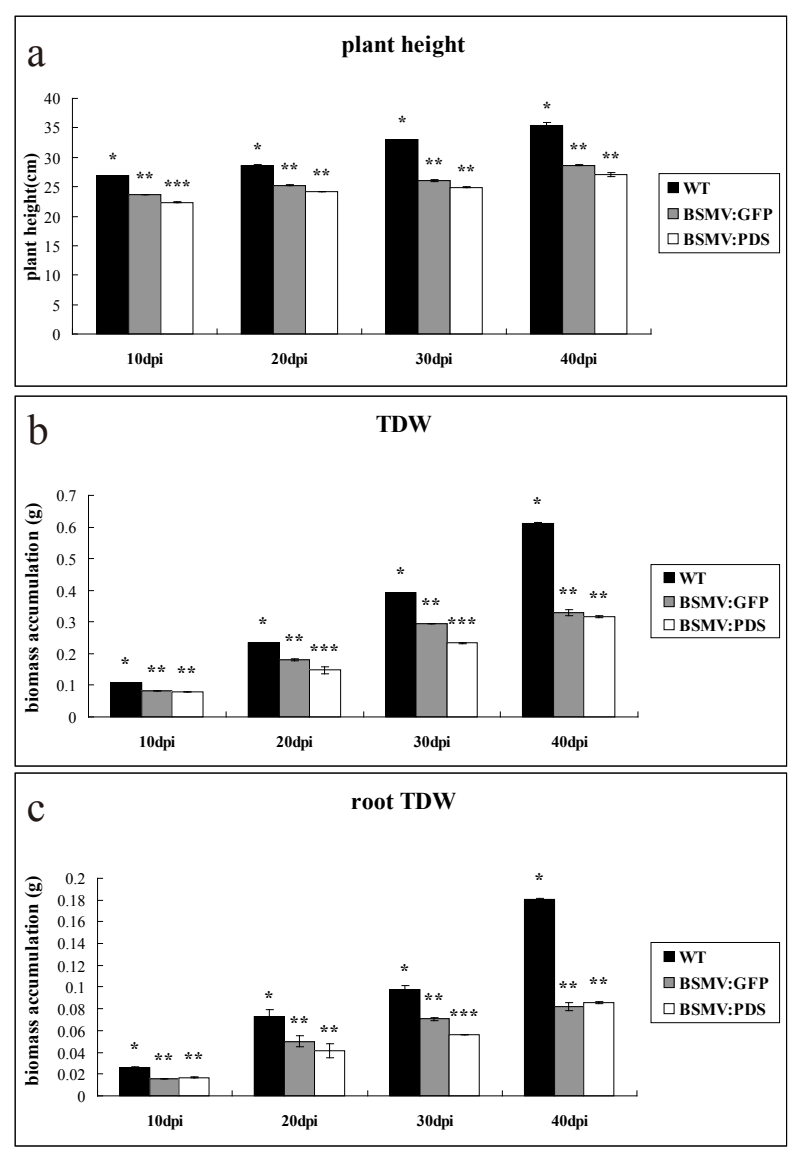

Fig. 3 Comparison of plant height and biomass accumulation of BSMV-infected plants and mock-inoculated WT control plants. a The height of BSMV-infected plants and mock-inoculated wild type (WT) control plants at 10,20, 30 and 40 days post inoculation (dpi). $\mathbf{b}$ The biomass accumulated of BSMV-infected plants and mock-inoculated WT control plants at 10, 20, 30 and 40 dpi. c The biomass accumulated of the roots of BSMV-infected plants and mock-inoculated WT control plants at 10, 20, 30 and 40 dpi. All data represent the average of three experiments with at least 6 replicates. Data are shown as means $\pm S E(n=3)$. The marker ${ }^{*}, * *$ and ${ }^{* * *}$ indicate that the means are significantly different at $P=0.05$ as determined by the least significant difference (LSD) test using Tukey's test (SPSS package, version 17.0). WT - mock-inoculated WT control plants; BSMV:GFP - plants inoculated by BSMV:GFP vector; BSMV:PDS - plants inoculated by BSMV:PDS vector.

of BSMV:GFP-inoculated plants at 10 and 20 dpi (Fig. 5b). These results indicated that the highly suppressed expression of PDS may impair the water retention capacity of hulless barley.

\section{The silencing efficiency and the stability of \\ BSMV-VIGS in Tibetan hulless barley}

The silencing efficiency of BSMV-VIGS under our experimental condition was checked by RT-qPCR from 7 to $60 \mathrm{dpi}$ using $P D S$ as an indicator. From 7 to $17 \mathrm{dpi}$, the expression level of $P D S$ in BSMV:PDS-inoculated plants was much lower than that of the BSMV:GFP-inoculated controls ( $4.46 \%$ to $10.20 \%$ of the latter). The PDS expression level in BSMV:PDS-inoculated plants increased gradually from 25 to $45 \mathrm{dpi}$ and maintained at a relatively higher level after $45 \mathrm{dpi}$
(Fig. 6), although this was still lower than the expression observed for BSMV:GFP. The leaves of BSMV:PDS-inoculated plants showed the classic white photo-bleaching phenotype from 10 to $40 \mathrm{dpi}$, indicating that the BSMV-VIGS worked well and the silencing phenotype could be maintained at least 40 days (Fig. 4).

The stability of BSMV-VIGS was investigated by checking the PCR products of BSMV:PDS-inoculated plants from 7 to 60 dpi by agarose gel electrophoresis. All the products amplified prior to $45 \mathrm{dpi}$ showed a single band with an expected size of around $400 \mathrm{bp}$ (Fig. 7), while the products after $40 \mathrm{dpi}$ had another obscure band at about $200 \mathrm{bp}$. The sequencing result showed that the PCR products were composed of the whole PDS insert which was designed for silencing and some of the flanking BSMV- $\gamma$ sequences (Fig. S2). In all, these results indicated that the designed PDS insert existed in almost all BSMV:PDS-inoculated plants from 7 to $60 \mathrm{dpi}$, and suggested that the stability of BSMV:PDS under our condition is acceptable before $40 \mathrm{dpi}$.

\section{Discussion}

\section{The pattern of BSMV accumulation in Tibetan hulless barley}

Virus accumulation in plants is regulated by the balance of defense and counter-defense mechanisms [26]. At the very beginning of the infection, when the amount of BSMV is low, the virus may not be detected by the defense system [27] and thus accumulates quickly. When viral dsRNA is abundant, the RNA-induced silencing complex (RISC) begins to target viral RNA. The virus accumulation is then slowed down and even declined $[27,28]$. In this study, BSMV accumulation showed this similar pattern where the virus reproduced at a peak rate from 7 to $11 \mathrm{dpi}$ and declined rapidly from 11 to $17 \mathrm{dpi}$. After $25 \mathrm{dpi}$, BSMV was rebalanced to a lower but relatively stable level.

\section{The impact of BSMV on vegetative growth and leaf morphology}

Previous researches indicated that virus infection could impair photosynthesis, reduce chlorophyll content, decrease activities of some photosynthetic enzymes, elevate sugar or starch contents [29-31] and reduce plant growth rate. In our study, the biomass accumulation was significantly retarded after BSMV infection. Although we suspected that after the virus level decreased, the biomass accumulation of BSMV infected plants would become comparable to the controls, the final results clearly indicated that the gap of TDW between BSMV infected plants and controls increased.

As BSMV affects plants in a systemic manner, we also checked the root system of the infected plants. The results showed that the root TDW of BSMV infected plants were also significantly less than that of WT controls. This may not be so important when scoring drought tolerance by a detached leaf assay, but may impact on other drought related assays.

Almási et al. [14] reported that BSMV infection can accelerated senescence. In our study, we noticed that the tip of new leaves lost water and withered at $10 \mathrm{dpi}$. Cells in new leaves senesced faster than those in mature leaves, suggesting that BSMV-VIGS analysis of genes related to the leaf morphology is probably not appropriate before $10 \mathrm{dpi}$. 


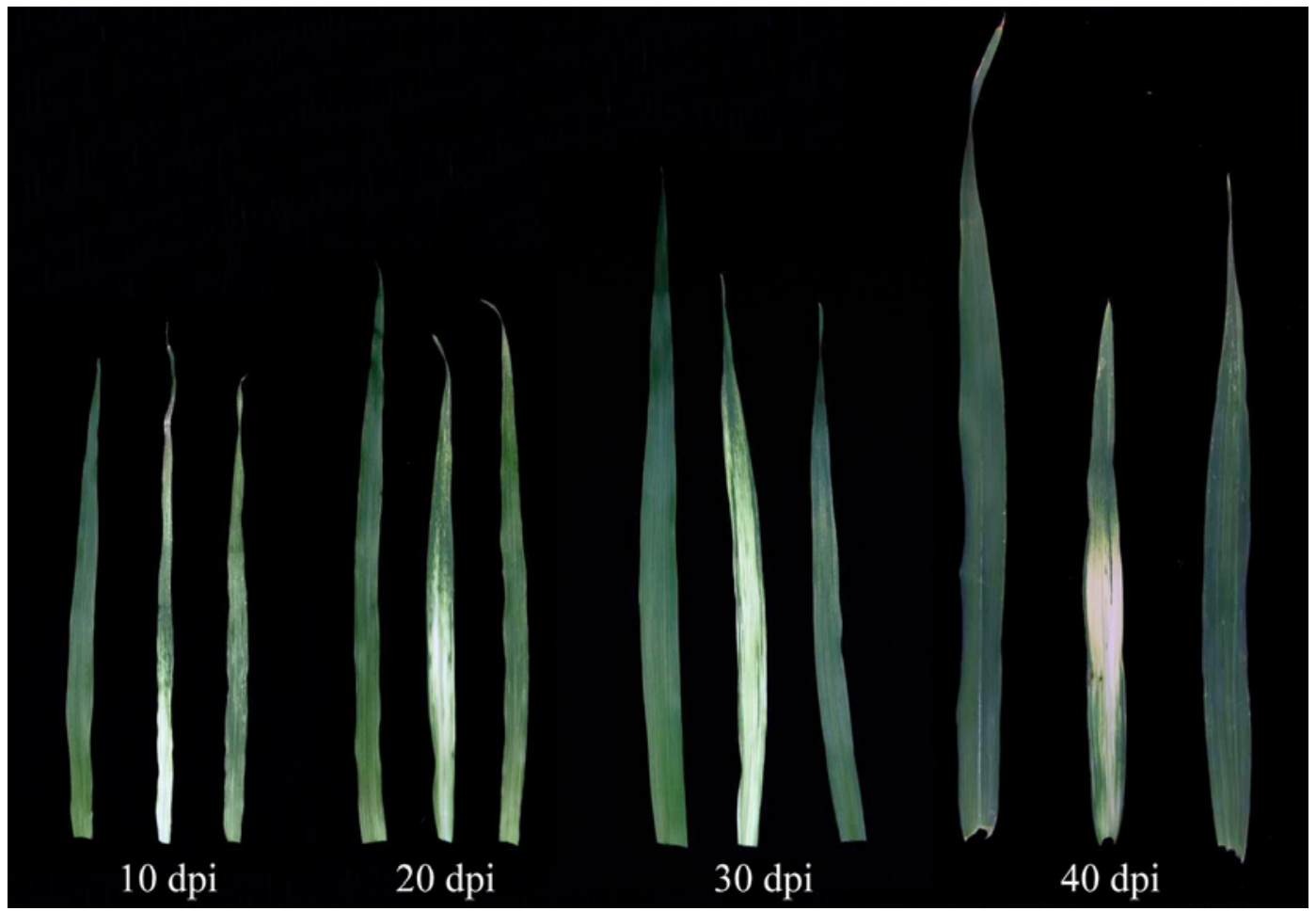

Fig. 4 Comparison of the leaf morphology of BSMV-infected plants and mock-inoculated wild type (WT) control plants. Leaves of mock-inoculated WT control plants, BSMV:PDS-inoculated and BSMV:GFP-inoculated plants (from left to right) at 10, 20, 30 and 40 days post inoculation (dpi), respectively.
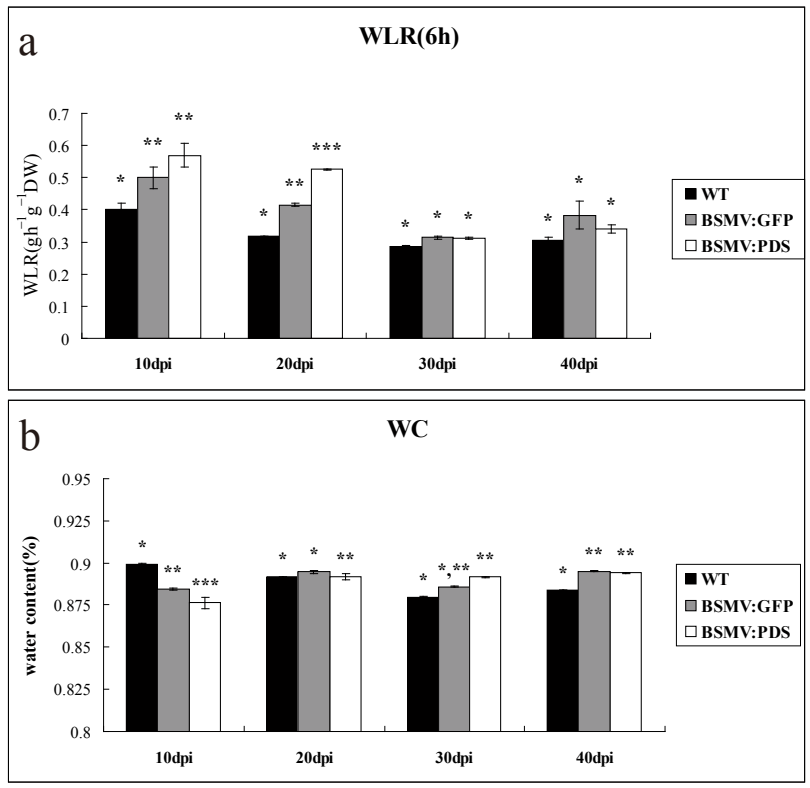

Fig. 5 Comparison of water loss rate (WLR) and water content (WC) of BSMV-infected plants and mock-inoculated wild type (WT) control plants. a The 6-h WLR of BSMV-infected plants and mock-inoculated WT control plants at 10,20,30 and 40 days post inoculation (dpi). $\mathbf{b}$ The WC of BSMV-infected plants and mock-inoculated WT control plants at 10, 20, 30 and 40 dpi. All data represent the average of three experiments with at least 6 replicates. Data are shown as means $\pm S E(n=3)$. The marker ${ }^{*},{ }^{* *}$ and ${ }^{* * *}$ show that the means are significantly different at $P=0.05$ as determined by the least significant difference (LSD) test using Tukey's test (SPSS package, version 17.0). WT - mock-inoculated WT control plants; BSMV:GFP - plants inoculated by BSMV:GFP vector; BSMV:PDS - plants inoculated by BSMV:PDS vector.

\section{The relationship between BSMV accumulation and its impacts on water holding capacity}

Our data indicated that the 6-h WLR of BSMV infected plants was significantly higher, while the WC of BSMV infected plants was significantly lower than the controls at $10 \mathrm{dpi}$, suggesting that the high accumulation of BSMV from 7 to 11 dpi greatly impacted the water holding capacity. When virus accumulation dropped from 11 to $17 \mathrm{dpi}$, its impact on water holding capacity also weakened. As our data indicated, the WC of BSMV:GFP infected plants had improves and had no significant difference compared to control plants at $20 \mathrm{dpi}$. After $25 \mathrm{dpi}$, the reproduction of BSMV virus declined gradually and became stable and its impact on WLR and WC also reduced to an undetectable level. These results suggested that the restricted reproduction of BSMV had only marginal impact on the water retention capacity of hulless barley seedlings. Therefore the best time to compare phenotypic changes related to water status is after 25 dpi.

As our results indicated that the silence of PDS impaired the water retention capacity of hulless barley at 10 and $20 \mathrm{dpi}$. Therefore, the PDS-silenced plants were not suitable for being a control when analyzing water status related genes before $20 \mathrm{dpi}$.

The prolonged VIGS obtained by lower temperature and high humidity

Previous studies showed that VIGS persists for longer if there is a continuous presence of the virus [5,32,33], however if the viral infection symptoms disappeared, the subsequent gene silencing phenotype would also disappear. It was reported that the most efficient time period for VIGS 


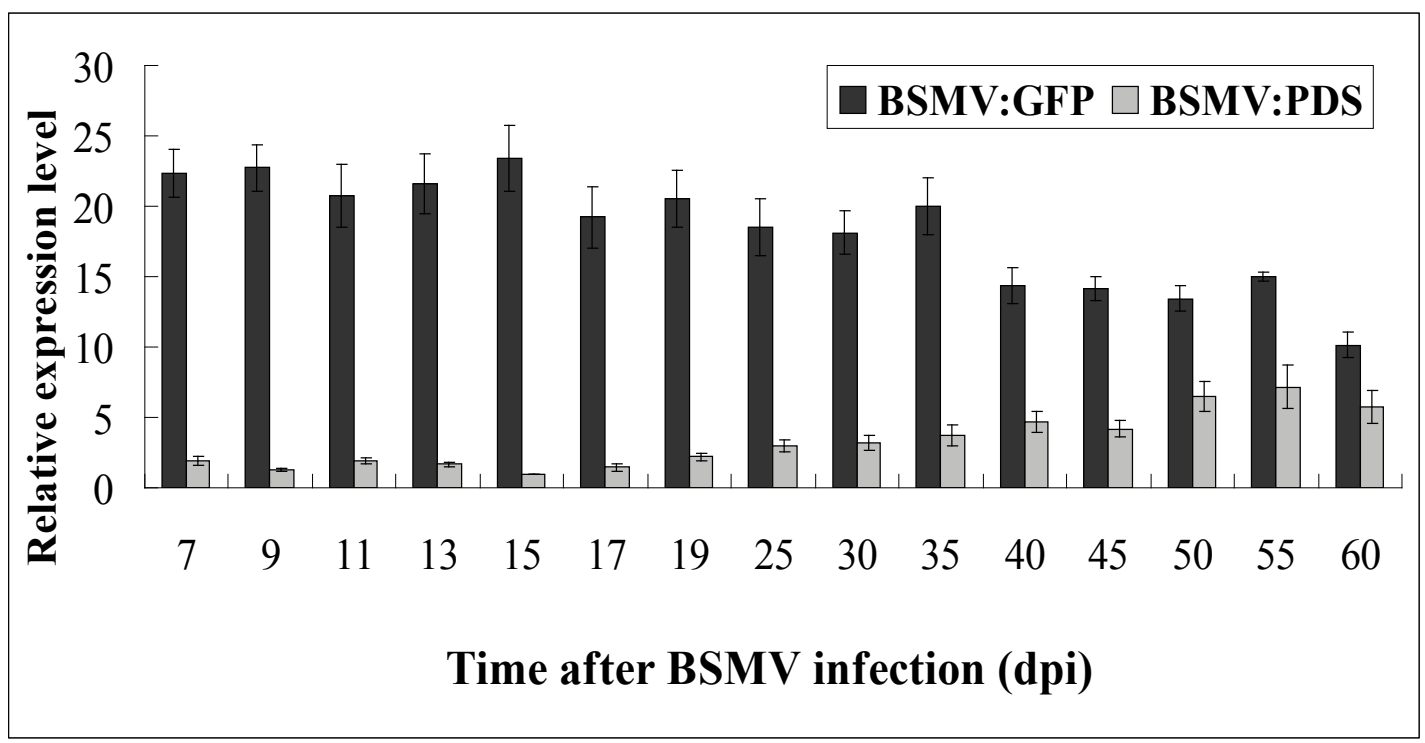

Fig. 6 Expression of Phytoene desaturase (PDS) in BSMV:GFP-inoculated plants and BSMV:PDS-inoculated control plants from 7 to 60 days post inoculation (dpi). The relative expression level of PDS in BSMV:GFP-inoculated plants and BSMV:PDS-inoculated control plants were analyzed by quantitative reverse transcription polymerase chain reaction (RT-qPCR) using elongation factor $1 \alpha(E F)$ as the reference from 7 to 60 dpi. Each sample contained newly grown leaves from at least 5 individual plants. All data represent the average value of three technical repeats and are shown as the means $\pm S D(n=3)$. BSMV:GFP - plants inoculated by BSMV:GFP vector; BSMV:PDS - plants inoculated by BSMV:PDS vector.

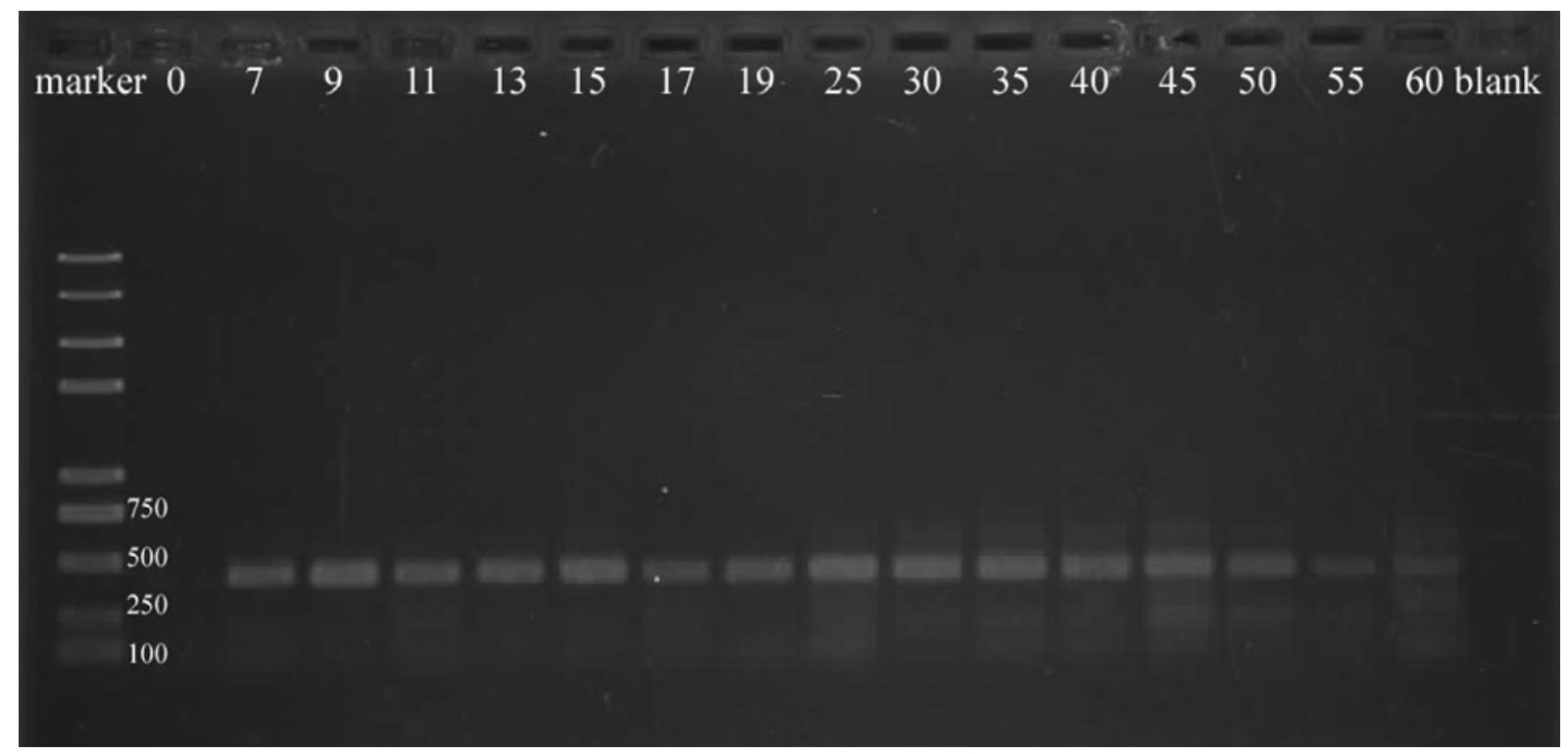

Fig. 7 The PCR products of PDSs of BSMV:PDS-inoculated plants from 7 to 60 days post inoculation (dpi). Agarose gel electrophoresis of the PCR products of using PDSs as the primer and the cDNA of BSMV:PDS-inoculated plants (from 7 to 60 dpi) as the templates. The predicted PCR product is $396 \mathrm{bp}$ in length, including both the PDS insert and part of the BSMV- $\gamma$ sequences as well. 0 - mock-inoculated wild type plant; $7,9,11,13,15,17,19,25,30,35,40,45,50,55,60$ - BSMV:PDS-inoculated plants from 7 to 60 dpi; blank - water template.

is within 3 weeks [34] and the efficiency of VIGS decreased after 1 month when plants start to recover from silencing [22]. The results of this study suggested that the best time for highly efficient silencing is from 7 to $17 \mathrm{dpi}$. The results also indicated that the most significant impacts of BSMV on the water status occurred prior to $25 \mathrm{dpi}$. This severely limited the potential for the conventional BSMV-VIGS assay to analyze drought related candidate genes. It was reported that lower temperatures can lead to better silencing phenotypes and targeted gene silencing [32,35-37]. Compared with the experimental condition of our previous BSMV-VIGS study [23], we found that by adjusting greenhouse temperatures from $24 \pm 1^{\circ} \mathrm{C}$ to $22 \pm 1^{\circ} \mathrm{C}$, the time period for efficient BSMVVIGS can be maintained to at least 40 days after inoculation. 
Furthermore, Cakir and Tör [37] reported that the PDS bleaching can be extend further to the forth leaves and to the tillering leaves of plants treated at the lower temperatures. In our tests, we also noticed that the PDS-silencing phenotype on some plants can even persisted to $150 \mathrm{dpi}$ (the initial shoot died, but the BSMV-VIGS still persisted in the tiller). Fu et al. [35] indicated that low humidity (30\%) enhanced the silencing of PDS. But in our experiment, the rate of successful infection was extremely low under the low relative humidity of $30 \%$ (data not shown). On the contrary, we achieved much better infection rate and good silencing efficient with a higher relative humidity of $70 \pm 10 \%$.

\section{The unstable BSMV}

The uneven distribution of BSMV in infected plants has been reported by many researchers [14,38]. The silencing induced by BSMV is not uniform from tissue to tissue, plant to plant or from experiment to experiment, and the phenotype of VIGS is not very stable $[39,40]$. Through our observation, the instability of VIGS is exacerbated after 40 dpi, a small part of PDS-silenced plants had completely lost the photo-bleaching phenotype, and some even lost the classic phenotype of BSMV infection (stripes and mosaics on leaves). While most of the plants retained their photobleaching phenotype until $60 \mathrm{dpi}$, the color of leaves turned from white into a green-white mix with only a few individuals retaining pure white leaves. The result of agarose gel electrophoresis also showed that the products after $40 \mathrm{dpi}$ had

\section{Acknowledgments}

We thank Chengdu Institute of Biology, Chinese Academy of Sciences for the Senior Research Fellowship award. Prof. Daowen Wang of Institute of Genetics and Developmental Biology, Chinese Academy of Sciences, Beijing, are greatly acknowledged for providing BSMV vectors. We sincerely acknowledge Dr. Bin Li for technical expertise and advice on BSMV inoculation. Thanks to Dr. Garry Rosewarne for English corrections. This work was supported by National Science \& Technology Pillar Program (2012BAD03B00), P.R. China and West Light Foundation of The Chinese Academy of Sciences.

\section{Authors' contributions}

The following declarations about authors' contributions to the research have been made: designed the research: JJL, HL; carried out most of the experiments: JJL; XC; analyzed the data and drafted the paper: JJL, SYY; supplied with hulless barley material and took the photos: GBD; helped to revise the manuscript: HHZ, GBD, ZFP; gave the final approval of the version to be published: MQY, HL.

\section{Competing interests}

No competing interests have been declared.

\section{Supplementary material}

The following supplementary material for this article is available online at http://pbsociety.org.pl/journals/index.php/asbp/rt/suppFiles/ asbp.2014.033/0:

1. Tab. S1: the sequence of BSMV:GFP.

2. Tab. S2: the sequence of BSMV:PDS

3. Fig. S1: schematic representation of barley stripe mosaic virus (BSMV) genome organization.

4. Fig. S2: sequencing result of the PCR product using PDSs from BSMV:PDS-inoculated plants. a second band, suggesting that some of plants had begun to lose the PDS insert on BSMV- $\gamma$ vector. Considering that the efficiency of BSMV-VIGS was relative low and the instability of VIGS has also been exacerbated after $40 \mathrm{dpi}$, we suggest it is necessary to finish data sampling before $40 \mathrm{dpi}$ and to use large numbers of infected plants for statistical analysis.

\section{Summary}

BSMV accumulated at high level from 7 to $13 \mathrm{dpi}$ and significantly impacted the water holding capacity of Tibetan hulless barley. The virus reproduction level declined and became relatively stable after $25 \mathrm{dpi}$, correlating with reduced impacts on WLR and WC. For the purpose of maintaining efficient BSMV-VIGS for extended periods, we put our inoculated plants under a lower temperature and higher relative humidity condition. The efficiency and the stability of BSMV-VIGS were checked, and proved to be acceptable for VIGS prior to $40 \mathrm{dpi}$. Thus, we conclude that the optimal time period for testing the function of drought stress related genes is between 25 and $40 \mathrm{dpi}$. As the vegetative growth was affected by the BSMV virus throughout the experiments, the study on related genes should be carefully interpreted, regardless of whether the gene is expressed in the aboveground parts of the plant or in the roots. We suggest that it is more reliable if different control groups and large numbers of infected plants can be employed.

\section{References}

1. Kumagai M, Donson J, Della-Cioppa G, Harvey D, Hanley K, Grill L. Cytoplasmic inhibition of carotenoid biosynthesis with virus-derived RNA. Proc Natl Acad Sci USA. 1995;92(5):1679-1683. http://dx.doi. org/10.1073/pnas.92.5.1679

2. Ratcliff F, Harrison BD, Baulcombe DC. A similarity between viral defense and gene silencing in plants. Science. 1997;276(5318):1558-1560. http://dx.doi.org/10.1126/science.276.5318.1558

3. Baulcombe DC. Fast forward genetics based on virus-induced gene silencing. Curr Opin Plant Biol. 1999;2(2):109-113. http://dx.doi. org/10.1016/S1369-5266(99)80022-3

4. Burch-Smith TM, Anderson JC, Martin GB, Dinesh-Kumar SP. Applications and advantages of virus-induced gene silencing for gene function studies in plants. Plant J. 2004;39(5):734-746. http://dx.doi. org/10.1111/j.1365-313X.2004.02158.x

5. Lee WS, Hammond-Kosack KE, Kanyuka K. Barley stripe mosaic virus-mediated tools for investigating gene function in cereal plants and their pathogens: VIGS, HIGS and VOX. Plant Physiol. 2012;160(2):582-590. http://dx.doi.org/10.1104/pp.112.203489

6. Holzberg S, Brosio P, Gross C, Pogue GP. Barley stripe mosaic virus-induced gene silencing in a monocot plant. Plant J. 2002;30(3):315-327. http://dx.doi.org/10.1046/j.1365-313X.2002.01291.x

7. Lacomme C, Hrubikova K, Hein I. Enhancement of virusinduced gene silencing through viral-based production of inverted-repeats. Plant J. 2003;34(4):543-553. http://dx.doi. org/10.1046/j.1365-313X.2003.01733.x

8. Scofield SR, Huang L, Brandt AS, Gill BS. Development of a virusinduced gene-silencing system for hexaploid wheat and its use in functional analysis of the $\mathrm{Lr} 21$-mediated leaf rust resistance pathway. Plant Physiol. 2005;138(4):2165-2173. http://dx.doi.org/10.1104/ pp.105.061861

9. Hein I, Barciszewska-Pacak M, Hrubikova K, Williamson S, Dinesen $\mathrm{M}$, Soenderby IE, et al. Virus-induced gene silencing-based functional 
characterization of genes associated with powdery mildew resistance in barley. Plant Physiol. 2005;138(4):2155-2164. http://dx.doi. org/10.1104/pp.105.062810

10. Hu P, Meng Y, Wise RP. Functional contribution of chorismate synthase, anthranilate synthase, and chorismate mutase to penetration resistance in barley-powdery mildew interactions. Mol Plant Microbe Interact. 2009;22(3):311-320. http://dx.doi.org/10.1094/ mpmi-22-3-0311

11. Meng Y, Moscou MJ, Wise RP. Blufensin1 negatively impacts basal defense in response to barley powdery mildew. Plant Physiol. 2009;149(1):271-285. http://dx.doi.org/10.1104/pp.108.129031

12. Scofield SR, Nelson RS. Resources for virus-induced gene silencing in the grasses. Plant Physiol. 2009;149(1):152-157. http://dx.doi. org/10.1104/pp.108.128702

13. Cakir C, Gillespie ME, Scofield SR. Rapid determination of gene function by virus-induced gene silencing in wheat and barley. Crop Sci. 2010;50(S1):S-77-S-84. http://dx.doi.org/10.2135/cropsci2009.10.0567

14. Almási A, Apatini D, Bóka K, Böddi B, Gáborjányi R. BSMV infection inhibits chlorophyll biosynthesis in barley plants. Physiol Mol Plant Pathol. 2000;56(6):227-233. http://dx.doi.org/10.1006/ pmpp.2000.0266

15. Bennypaul HS. Genetic analysis and functional genomic tool development to characterize resistance gene candidates in wheat (Triticum aestivum L.) [PhD thesis]. Pullman, WA: Washington State University; 2008.

16. Senthil-Kumar M, Mysore KS. New dimensions for VIGS in plant functional genomics. Trends Plant Sci. 2011;16(12):656-665. http:// dx.doi.org/10.1016/j.tplants.2011.08.006

17. Qian G, Han Z, Zhao T, Deng G, Pan Z, Yu M. Genotypic variability in sequence and expression of HVA1 gene in Tibetan hulless barley, Hordeum vulgare ssp. vulgare, associated with resistance to water deficit. Aust J Agric Res. 2007;58(5):425-431. http://dx.doi. org/10.1071/AR06300

18. Senthil-Kumar M, Rame Gowda HV, Hema R, Mysore KS, Udayakumar M. Virus-induced gene silencing and its application in characterizing genes involved in water-deficit-stress tolerance. J Plant Physiol. 2008;165(13):1404-1421. http://dx.doi.org/10.1016/j.jplph.2008.04.007

19. Demmig-Adams B, Adams Iii W. Photoprotection and other responses of plants to high light stress. Annu Rev Plant Physiol Plant Mol Biol. 1992;43:599-626. http://dx.doi.org/10.1146/annurev. pp.43.060192.003123

20. Ruiz MT, Voinnet O, Baulcombe DC. Initiation and maintenance of virus-induced gene silencing. Plant Cell. 1998;10(6):937-946. http:// dx.doi.org/10.1105/tpc.10.6.937

21. Angell SM, Baulcombe DC. Technical advance: potato virus X amplicon-mediated silencing of nuclear genes. Plant J. 1999;20:357-362. http://dx.doi.org/10.1046/j.1365-313X.1999.00597.x

22. Ratcliff F, Martin-Hernandez AM, Baulcombe DC. Technical advance: tobacco rattle virus as a vector for analysis of gene function by silencing. Plant J. 2001;25(2):237-245. http://dx.doi. org/10.1046/j.0960-7412.2000.00942.x

23. Liang J, Deng G, Long H, Pan Z, Wang C, Cai P, et al. Virus-induced silencing of genes encoding LEA protein in Tibetan hulless barley (Hordeum vulgare ssp. vulgare) and their relationship to drought tolerance. Mol Breed. 2012;30(1):441-451. http://dx.doi.org/10.1007/ s11032-011-9633-3

24. Zhou H, Li S, Deng Z, Wang X, Chen T, Zhang J, et al. Molecular analysis of three new receptor-like kinase genes from hexaploid wheat and evidence for their participation in wheat hypersensitive response to stripe rust fungus infection. Plant J. 2007;52(3):420-434. http:// dx.doi.org/10.1111/j.1365-313X.2007.03246.x

25. Haupt S, Duncan GH, Holzberg S, Oparka KJ. Evidence for symplastic phloem unloading in sink leaves of barley. Plant Physiol. 2001;125(1):209-218. http://dx.doi.org/10.1104/pp.125.1.209

26. Maule A, Leh V, Lederer C. The dialogue between viruses and hosts in compatible interactions. Curr Opin Plant Biol. 2002;5(4):279-284. http://dx.doi.org/10.1016/S1369-5266(02)00272-8

27. Lu R, Malcuit I, Moffett P, Ruiz MT, Peart J, Wu AJ, et al. High throughput virus-induced gene silencing implicates heat shock protein 90 in plant disease resistance. EMBO J. 2003;22(21):5690-5699. http:// dx.doi.org/10.1093/emboj/cdg546

28. Voinnet O. RNA silencing as a plant immune system against viruses. Trends Genet. 2001;17(8):449-459. http://dx.doi.org/10.1016/ S0168-9525(01)02367-8

29. Montalbini P, Lupattelli M. Effect of localized and systemic tobacco mosaic virus infection on some photochemical and enzymatic activities of isolated tobacco chloroplasts. Physiol Mol Plant Pathol. 1989;34(2):147-162. http://dx.doi.org/10.1016/0885-5765(89)90022-2

30. Funayama S, Sonoike K, Terashima I. Photosynthetic properties of leaves of Eupatorium makinoi infected by a geminivirus. Photosynth Res. 1997;53(2-3):253-261. http://dx.doi. org/10.1023/A:1005884007183

31. Funayama S, Terashima I. Effects of geminivirus infection and growth irradiance on the vegetative growth and photosynthetic production of Eupatorium makinoi. New Phytol. 1999;142(3):483-494. http:// dx.doi.org/10.1046/j.1469-8137.1999.00418.x

32. Bruun-Rasmussen M, Madsen CT, Jessing S, Albrechtsen M. Stability of Barley stripe mosaic virus-induced gene silencing in barley. Mol Plant Microbe Interact. 2007;20(11):1323-1331. http://dx.doi. org/10.1094/mpmi-20-11-1323

33. Senthil-Kumar M, Mysore KS. Virus-induced gene silencing can persist for more than 2 years and also be transmitted to progeny seedlings in Nicotiana benthamiana and tomato. Plant Biotechnol J. 2011;9(7):797806. http://dx.doi.org/10.1111/j.1467-7652.2011.00589.x

34. Ryu CM, Anand A, Kang L, Mysore KS. Agrodrench: a novel and effective agroinoculation method for virus-induced gene silencing in roots and diverse Solanaceous species. Plant J. 2004;40(2):322-331. http://dx.doi.org/10.1111/j.1365-313X.2004.02211.x

35. Fu DQ, Zhu BZ, Zhu HL, Zhang HX, Xie YH, Jiang WB, et al. Enhancement of virus-induced gene silencing in tomato by low temperature and low humidity. Mol Cells. 2006;21:153-160.

36. Tuttle JR, Idris AM, Brown JK, Haigler CH, Robertson D. Geminivirusmediated gene silencing from Cotton leaf crumple virus is enhanced by low temperature in cotton. Plant Physiol. 2008;148(1):41-50. http:// dx.doi.org/10.1104/pp.108.123869

37. Cakir C, Tör M. Factors influencing Barley stripe mosaic virusmediated gene silencing in wheat. Physiol Mol Plant Pathol. 2010;74(34):246-253. http://dx.doi.org/10.1016/j.pmpp.2010.04.001

38. Lin NS, Langenberg W. Distribution of Barley stripe mosaic virus protein in infected wheat root and shoot tips. J Gen Virol. 1984;65(12):22172224. http://dx.doi.org/10.1099/0022-1317-65-12-2217

39. Campbell J, Huang L. Silencing of multiple genes in wheat using Barley stripe mosaic virus. J Biotech Res. 2010;2:12-20.

40. Huang C, Qian Y, Li Z, Zhou X. Virus-induced gene silencing and its application in plant functional genomics. Sci China Life Sci. 2012;55(2):99-108. http://dx.doi.org/10.1007/s11427-012-4280-4 